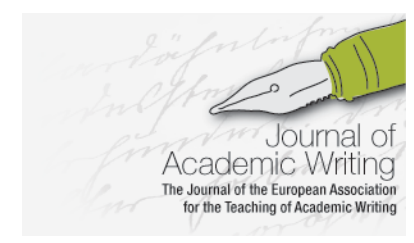

\title{
Creating Participatory Writing Cultures in UK Higher Education
}

\author{
Lisa Clughen \\ Nottingham Trent University, UK \\ Christine Hardy \\ Nottingham Trent University, UK
}

\begin{abstract}
One particularly difficult area for higher education students is writing appropriately for their respective disciplines. As writing is a social, cultural and dialogic act, writing support should create learning events that will allow for useful social exchange of ideas within the appropriate disciplinary cultures. Indeed, many claims are made in favour of disciplinary-based writing support: students will become more engaged with their subjects, will develop as critical thinkers and, through debate, will produce scripts which are more likely to warrant them voice within their disciplinary cultures.

In the study described in this paper, two academics from Art and Design and Humanities in a UK university used different techniques to create participatory writing cultures in the classroom. Despite different settings, similar issues arose that are not fully addressed in the literature on writing development, including student non-engagement with active learning; issues with the development of critical skills; and student agency. The authors will discuss their findings by drawing on student feedback and their own reflection on the teaching sessions.
\end{abstract}

\section{Introduction}

Many students arrive at university in the UK poorly prepared for the type of studying and learning they will encounter (Cook and Leckey 1999) as the ' $A$ ' levels, preparatory exams taken at school, are too narrow a preparation for the demands of higher education, with little or no emphasis on teamwork or independence of approach (Roberts and Higgins 1992 cited in Lowe and Cook 2003). A large minority of students expect teaching styles associated with school (Lowe and Cook 2003: 63), where often there is 'strong parental and teacher support for students both in advising them how to study and providing sources of external motivation' (Cook and Leckey 1999: 169).

In addition, teaching and assessment styles in schools may lend themselves to the development of a set of study skills that persist into university but are no longer appropriate for the more independent styles of learning in a tertiary environment. According to Cook and Leckey, at university, students 'value a simple approach in which staff present classes with precise information which can be easily translated into examination answers and assignments' (1999: 163) and 'are more focused on the material delivered by staff than on the wider subject' (1999: 164).

Many students, therefore, bring to university a 'meaning-making structure that holds all knowledge to be certain and possessed by external authority' (Hodge, Baxter Magolda and Haynes 2009: 18), and, consequently, they often trust others more than they trust themselves, seeking approval from others and following external formulae. University learning entails a shift from this uncritical acceptance of external authority to a critical analysis of authority, thereby establishing one's own internal authority and developing 'self-authorship, or the capacity to define one's beliefs, identity and social relations' (Hodge, Baxter Magolda and Haynes 2009: 16). This ability will enable students to evaluate 
information critically, form their own judgements and collaborate with others as higher education requires. To do this, students must understand the information they encounter, but often they do not as it is produced against a backdrop of unspoken assumptions, so they need frames of reference within which information is meaningful for them (Norton and Crowley 1995). These frames of reference are rarely highlighted by academics, though, being taken for granted by members of the knowledge community, so that students get very few clues to help them. However, 'the teacher, as a speaker of the specialist discourse, is able to "lend" students the capacity to frame meanings they cannot yet produce independently' (Norton and Crowley 1995: 172). Through repeatedly sharing meaning-making with speakers of the specialist discourse, students can come to internalise the frames of reference which are taken for granted: 'To acquire this fluency, [students] need opportunities to speak and write the discourse in the "presence" of a competent speaker who can, by responding, help to shape their usage' (Norton and Crowley 1995: 178).

When working with students on their writing, then, it is imperative that those involved have the disciplinary knowledge and experience that will foster deep critical evaluation. Concomitantly, writing development would also include collaboration with others as 'a lot of writing is about human contact' (Elbow in Bazerman et al. 2006). Human contact by its very nature is socio-cultural, and it is therefore argued that literacy itself (and writing is part of that literacy) is a socio-cultural act (Lankshear and Nobel 2005, Purves 1987, and Street 1984 and 2003). Brian Street, a key proponent of this sociocultural approach to literacy, sums up this point and emphasises that literacy is always social:

Literacy is a social practice, not simply a technical and neutral skill; [...] it is always embedded in socially constructed epistemological principles. [...] It is also always embedded in social practices, such as those of a particular job market or a particular educational context and the effects of learning that particular literacy will be dependent on those particular contexts (Street 2003: 77-78).

Conceptualising literacy as a socio-cultural act involves two key awarenesses:

- first, that becoming literate involves responding to the specific demands of the cultures in which literacy is used, so support for student writing needs to take place in the disciplinary context in which it occurs (Ganobcsik-Williams 2006, Haggis 2006, Street 1984 and Taylor et al. 1988) and

- second, that literacy is both social and an activity, rather than the direct transfer of the thoughts of a solitary individual onto a static, uncommunicative page (McLeod 2000: 2-4).

This study takes a reflective approach to the aforementioned literacy theories and reports on two writing groups in two different disciplines within a large UK university.

\section{Disciplinarity and Literacy}

Scholars in literacy studies who emphasise the cultural specificity, and in terms of student writing, the disciplinarity of literacy, point out that in order to write appropriately, students need to know how to set about their academic business, or how to be accepted members of a particular discipline (Penrose 2002: 6). This ability involves their knowing how to think in the discipline, how to approach their sources and then how to present their thoughts to others in discipline-appropriate ways. Writing, in other words, is bound up with issues of ontology, epistemology, disciplinary writing practices and discourse (Ganobcsik-Williams 2006, Haggis 2006, Lea and Street 1998: 162 and Warren 2002: 88). If students are to develop their writing, then they will need guidance through the writing processes involved in the different types of disciplinary writing they encounter. This insight was borne out by Hattie, Biggs and Purdie (1996) in their meta-analysis of learning skills interventions on student learning which supported the notion of situated cognition. They recommended that development activities should '(a) be in context, (b) use tasks within the same domain as the target content, (c) and promote a high degree of learner activity and metacognitive awareness' (Hattie, Biggs and Purdie1996: 131) and that to become effective, such activities should be embedded in the teaching context itself. 


\section{Literacy as a Social Activity}

A common pedagogical response to the sociality of literacy is to argue for talk as a means of fostering both socialisation into, and active, creative participation within, a disciplinary culture (Bazerman et al. 2006, Elbow 2008 and Lillis 2006). Students will need to engage in talk about the practices involved in writing for a particular discipline, the content of their disciplinary writing, and about the often unfamiliar language they are encountering as they prepare their scripts. Offering spaces for supportive human interaction in the writing process will also provide a platform from which to address the personal and emotional aspects of the writing process. Anxieties, doubts and fear that can ensue (Davies, Swinburne and Williams 2006) from an engagement with a process that is both a 'self creating' activity (Bazerman in Bazerman et al. 2006) and one in which writers present their selves to others. Literacy theorists, therefore, argue quite definitely that writing improves if people are able to interact socially (Bazerman et al. 2006) and suggested pedagogies for peer and group support as essential to effective writing support abound (Bean 2001: 149-168).

\section{In Favour of Participatory Writing Cultures}

Many positive claims are made for participatory writing cultures. Writing Across the Curriculum (WAC) theorists (see for example, Bean 2001) typically argue that using writing in the learning process can improve many aspects of learning and performance for the student including:

1. the learning of course material,

2. engagement with the course,

3. thinking skills,

4. organisational skills (both mental and written),

5. communication skills,

6. written skills at paragraph, grammar and sentence level.

WAC techniques promise equally positive outcomes for staff, particularly in terms of creating an environment which would improve staff-student relationships, thereby fostering conditions for student self-authorship:

professors who successfully integrate writing and critical thinking tasks into their courses often report a satisfying increase in their teaching pleasure: class discussions are richer, students are more fully engaged in their learning and the quality of their performance improves (Bean 2001: 1).

There is, however, a cautious note in the literature (Clughen and Connell 2008), which points out that students are increasingly instrumental and aware of their customer status, and want staff to use contact time to impart their own expert knowledge. However, the overriding representation of embedded literacies in literacy scholarship is that they are essential to engender successful Communities of Practice (Wenger 1998), enabling students to become co-producers of knowledge.

\section{Method}

To engender the aforementioned participatory cultures, student writing groups were introduced in two Schools within a large UK university. In Art and Design, the writing event formed part of a compulsory module and was a one-off exercise, and in Arts and Humanities, it was an ongoing exercise in which students engaged voluntarily. For both subject areas, the intention was to involve the students in disciplinary writing requirements in a way that would embrace where they currently were in their learning by engaging them in short, formative tasks. Students worked in pairs, small groups and whole groups during the exercises, which comprised both discussion and writing with an emphasis on both writing to learn and learning to write in the discipline via, for example, the co-production of writing. In this way, the students were invited to discuss the conventions of writing and academic discourse in their subject area. Neither lecturer who led the sessions had responsibility for the assessment of these students at this point, but both worked closely with the subject teams, or had direct experience of teaching on these programmes and within the subject areas. 
Student feedback was collected through questionnaires and student discussions. The University ethical guidelines were followed both in the collection of feedback and the following reporting of results.

\section{Outcomes}

Student feedback on the sessions was positive with students valuing the style of learning, particularly the group discussions/interactions with other students and the practical focus (58\%, $\mathrm{n}=58$ in Art and Design):

The group is a great chance to discuss ideas, themes, etc., in a very relaxed environment. This I think, allows people to be more open to say and discuss things they think may be perceived as quite trivial, or they may be afraid to raise in a seminar/lecture (Final year student, Arts and Humanities).

Students also felt that they had learnt about academic writing, both structure and skills $(96 \%, n=58$ Art and Design) and that they could apply the learning in the future (96\%, $n=58$ Art and Design). In Arts and Humanities there was an improvement in marks:

My essay mark for the [...] module was higher than in any other third year module. I would relate this achievement directly to my engagement in the AWG [Academic Writers' Group] also, as mentioned before the things we learned from the AWG can easily be transferred to other modules and assignments (Final year student).

Without your writers' group, I wouldn't have got a first on my [...] I feel my academic writing is much tighter now (Final year student).

Although student feedback was positive, the lecturers' reflection revealed some common themes regarding student engagement, either with the sessions and activities or with the wider programme of study. These have been categorised as follows:

- Lack of understanding/interest in subject content prevents dialogue: Some students did not understand or, on occasion, remember the lectures, and they did not do further reading around the subject.

- Instrumentality: Some students wanted to be told what to do and how to do it. They wanted much more tutor input, for example, in Art and Design $36 \%$ of students wanted more information, explanation and examples.

- Student agency: When invited to discuss their work, some students said 'I don't know or I don't know what I am trying to say', and frequently asked the lecturers for their opinions. Occasionally, lecturers' questions like 'Where are you going with this?', 'What are you trying to say here?' or 'What do you think this is about?' elicited little response from students.

- Lack of engagement with the learning activity/sessions: Some students did not engage with the session and the tutor had to keep reminding them what they were supposed to be doing.

- Lack of preparation for sessions: Some students did not prepare for the sessions, they did not bring work expected of them, or avoided attending the session if they had not undertaken the required preparation.

- Development of critical skills: Some students found the peer review process of their and other students' writing particularly difficult and were not prepared to be critical. 


\section{Discussion}

This study has highlighted some of the complexities of establishing and developing participatory writing cultures amongst students in higher education.

Students valued the human nature of the writing development events, particularly group discussions and interactions with other students. They saw the sessions as safe environments where they could both express and address their fears about, and their struggles with, writing. The sessions gave them an opportunity, through discussions with disciplinary practitioners, to enter into dialogic, questioning relationships with the disciplinary culture (Lillis 2006) and to begin to understand the frames of reference around their particular discipline (Norton and Crowley 1995).

As we said above, the literature also recognises increased satisfaction for staff who engage students with ideas (Bean 2001). Those moments when students fully supported each other through their individual struggles with writing without the interference of the lecturer, in other words, moments when genuine student participation rather than lecturer socialisation occurred, did indeed create the sense of pleasure in teaching of which Bean speaks. However, this was not the overriding experience.

It was also found that dialogic interaction did not always translate into self-authorship (Hodge, Baxter Magolda and Haynes 2009), with some participants using this interaction, rather, as a means to an end. Some students appeared to persist in their reference to external authorities such as their lecturers for knowledge, decision-making and validation of their work. There was thus a mismatch in expectations between the student and the lecturer: lecturers wanted students to take responsibility for their writing and to invite them into their learning and writing, whilst students frequently handed their agency over to the tutor. Arguably, then, bringing the human into writing (Elbow in Bazerman et al. 2006) risks allowing the students to position tutors as nurturers rather than co-collaborators and may prepare the ground for student instrumentality. Indeed, in some cases, it seemed that students had not moved on in their study skills from school when there was strong parental and teacher support (Cook and Leckey 1999), forcing instead the 'banking model' of education (Freire 1993).

In order to reflect on this, we should not underestimate the implications and consequences of the point that literacy is a cultural act. Students bring with them responses to literacy that have been developed in their wider literacy cultures. For the first-year students in this study, the lack of selfauthorship mentioned above might be due to a persistence with prior teaching, learning and assessment styles (Cook and Leckey 1999) and for those in the final year, it might be due to assessment pressures. Moreover, for the students, events for academic writing constituted only a small part of a whole culture of their personal literacies. Student writing cultures consist not only of writing within their discipline, but also of other daily writing, such as texting friends, writing shopping lists, internet chat and instant messaging, Facebook, and notes to each other. Their overall literacy culture, therefore, consists of writing that is mainly in the vernacular and this does not extend necessarily or always easily into the writing demanded in university cultures. Expecting a wholesale embrace of a space that would allow them to develop the requisite practices and discourses for academic writing was, in some cases perhaps, to expect too much, for perhaps they were being asked to do something that was alien to their localised literacy practices.

The essential argument in all of this is that context is everything when creating participatory writing cultures. This concept can be divided both into the classroom context and the wider cultural context; and at various times in the writing groups discussed here, both contexts worked against the goals of the sessions described. In other words, the prior and present experiences of participants will impact on the outcomes of the sessions. Such outcomes, however, do not militate against the goals of participatory cultures, nor undermine those who would argue for social approaches to writing. The positive experiences described in the feedback on these writing events have encouraged both authors to believe that, as an academy, we do need to bring human contact into writing as, amongst other things, writing is an affective issue (Davies 2004). However, we do need to manage expectations of the outcomes of such participatory cultures both on the parts of students and of staff. 


\section{Conclusion}

The key point of this paper is that, if writing is a socio-cultural act, then it follows that the attitudes and approaches to writing developed in the students' and lecturers' wider socio-cultural contexts will be brought into the micro-culture of the participatory writing event. Conditions may be set up for students to participate and engage in a shared Community of Practice, but it does not follow that they will be either willing or have the culturally developed approaches to writing and study that enable them to embrace the social approach. Understanding student writing cultures is therefore essential to provide a bridge into specific disciplinary writing cultures.

The metaphor of the bridge is useful here as it connects attitudes to literacy developed in the students' wider culture with those of the localised writing culture. Speaking of spaces that allow for a development of learning in general, Kegan (1994: 43) describes this bridge as a 'holding environment':

that provides both welcoming acknowledgement to exactly who the person is right now as he or she is, and fosters the person's psychological evolution. As such, a holding environment is a tricky, transitional culture, an evolutionary bridge, a context for crossing over.

This concept, we have argued, also applies to participatory cultures for writing development. Kegan's point that such an environment is 'tricky' points to the complex and involved nature of establishing spaces that would enable students to make the transition into academic writing cultures, for elements of their wider writing cultures may have inculcated a dependence on external authorities and this may be brought into participatory writing cultures. Problematic as they may be, however, holding spaces for crossing over into academic literacy practices are essential if students are both to make the transition and then create their own literacy spaces within the academy. 


\section{References}

Bazerman, C., Elbow, P. Hillocks, G., and Blau, S. (2006) '50 Years of Research on Writing: What Have We Learned?' [online] available from $<$ http://www.youtube.com/watch?v=mrcq3dzt0Uk> [8 April 2010]

Bean, J. (2001) Engaging Ideas: The Professor's Guide to Integrating Writing, Critical Thinking, and Active Learning in the Classroom. San Francisco: Jossey-Bass

Clughen, L. and Connell, M. (2008) 'Writing and Resistance: Preliminary Findings from a Pilot Project to Embed Writing-Across-The-Curriculum in Social Theory at Nottingham Trent University'. 3rd International iPED Conference: Researching Academic Visions \& Realities. held 8-9 September 2008 at Coventry University, 16-21. available from $<$ https://curve.coventry.ac.uk/cu/items/0cd84b30-113e-2289-861b-3e01655cfc61/1/ iPED2008proceedings.pdf> [10 June 2011]

Cook, A. and Leckey, J. (1999) 'Do Expectations Meet Reality? A Survey of Changes in First-year Student Opinion'. Journal of Further and Higher Education 23 (2), 157-171

Davies, S., Swinburne, D. and Williams, G. (2006) Writing Matters: The Royal Literary Fund Report on Student Writing in Higher Education. London: Royal Literary Fund

Davies, S. (2004) Royal Literary Fund Fellowships: The Human Exchange. London: Royal Literary Fund [online]. available from <http://www.rlf.org.uk/fellowshipscheme/documents/TheHumanExchange.pdf?> [13 January 2011]

Elbow, P. (2008) 'Vulgar Eloquence: Enlisting Speech for Writing'. in The 12th Writing Development in Higher Education Conference, University of Strathclyde, 25-27 June 2008 [online] available from<video.strath.ac.uk/08/085-08-01.wvx> [8 April 2010]

Freire, P. (1993) Pedagogy of the Oppressed. New York: Continuum Books

Ganobcsik-Williams, L. (ed.) (2006) Teaching Academic Writing in UK Higher Education: Theories, Practices and Models. Basingstoke: Palgrave Macmillan

Haggis, T. (2006) 'Pedagogies for Diversity: Retaining Critical Challenge Amidst Fears of Dumbing Down'. Studies in Higher Education 31 (5) 521-535

Hattie, J; Biggs, J. and Purdie, N. (1996) 'Effects of Learning Skills Interventions on Student Learning: A Meta-Analysis'. Review of Educational Research 66 (2), 99-136

Hodge, D; Baxter Magolda, M. and Haynes, C. (2009) 'Engaged Learning: Enabling Self-Authorship and Effective Practice'. Liberal Education 95 (4), 16-23

Kegan, R. (1994) In Over Our Heads: The Mental Demands of Modern Life. Cambridge, Massachusetts: Harvard University Press.

Lankshear, C. and Nobel, M. (2005) New Literacies: Changing Knowledge and Classroom Learning. Maidenhead, Berks: OUP and McGraw-Hill Education

Lea, M. and Street, B. (1998) 'Student Writing in Higher Education: an Academic Literacies Approach'. Studies in Higher Education 23 (2) 157-172

Lillis, T. (2006) 'Moving Towards an "Academic Literacies" Pedagogy: Dialogues of Participation'. in Teaching Academic Writing in UK Higher Education: Theories, Practices and Models. ed. by Ganobcsik-Williams, L. Basingstoke: Palgrave Macmillan, 30-45 
Lowe, H. and Cook, A. (2003) 'Mind the Gap: Are Students Prepared for Higher Education?' Journal of Further and Higher Education, 27 (1), 53-76

McLeoD, S. H. (2000) 'Writing Across the Curriculum: An Introduction' [online]. in Writing Across the Curriculum: A Guide to Developing Programs. WAC Clearinghouse Landmark Publications in Writing Studies. ed. by McLeod, S. H. and Soven, M. available from <http://wac.colostate.edu/books/mcleod_soven/ >, 1-8 [13 June 2011]

Norton, L. S. and Crowley, C. M. (1995) 'Can Students be Helped to Learn How to Learn? An Evaluation of an Approaches to Learning Programme for First Year Degree Students'. Higher Education 29 (3), 307-328

Penrose, A. M. (2002) 'Academic Literacy Perceptions and Performance: Comparing First-Generation And Continuing-Generation College Students'. Research in the Teaching of English 36 (4), 437-461

Purves, A. C. (1987) 'Literacy, Culture and Community'. in The Future of Literacy in a Changing World. ed. by Wagner, D. Oxford: Pergamon Press, 216-232

Roberts, D. and Higgins, T. (1992) Higher Education: The Student Experience. The Findings of a Research Programme into Student Decision-Making And Consumer Satisfaction. Leeds: Heist-PCAS

Street, B. (1984) Literacy in Theory and Practice. Cambridge: CUP

Street, B. (2003) 'What's "New" in New Literacy Studies? Critical Approaches to Literacy in Theory and Practice'. Current Issues in Comparative Education 5 (2) [online] available from <http://www.tc.columbia.edu/crce/Archives/5.2/52Street.pdf> [2 April 2010]

Taylor, G., Ballard, B., Beasley V., Bock H. K., Clanchy, J. and Nightingale, P. (1988) Literacy by Degrees. Milton Keynes: SRHE/OUP

Warren, D. (2002) 'Curriculum Design in a Context of Widening Participation in Higher Education'. Arts and Humanities in Higher Education 1 (1) 85-99

Wenger, E. (1998) Communities of Practice: Learning, Meaning and Identity. Cambridge: CUP 